\title{
SOLUSI PREDIKSI MAHASISWA DROP OUT PADA PROGRAM STUDI SISTEM INFORMASI FAKULTAS ILMU KOMPUTER UNIVERSITAS BINA DARMA
}

\author{
Ade Putra \\ Fakultas Vokasi, Program Studi Komputerisasi Akuntansi \\ Universitas Bina Darma \\ Email: ade.putra@binadarma.ac.id
}

\begin{abstract}
ABSTRAK
Data mining merupakan salah satu pengetahuan yang bergerak di bidang penggalian dan pengkajian data, dimana data mining mampu memberikan solusi dalam pemecahan permasalahan, khususnya yang di hadapi oleh program studi Sistem Informasi Fakultas Ilmu Komputer guna menjamin agar mahasiswa Program Studi Sistem Informasi Fakultas Ilmu Komputer Universitas Bina Darma dapat lulus dengan tepat waktu. Adapun tahapan yang digunakan yaitu menggunakan konsep Knowledge Discovery in Database (KDD) yang terdiri dari Selection, PreProcessing, Transformation, Data Mining dan Interprestation / Evaluation. Pada penelitian ini digunakan metode Clasificassion dengan algoritma Decision Tree atau C4.5., Pada algoritma ini, hasil penilaian yang dipakai untuk menentukan Node sebagai kunci dalam menilai kelayakan mahasiswa yang Drop Out dilihat dari nilai Entropi dan Gain pada masing - masing attribute,. Adapun attribute yang digunakan untuk penilaian Entropi dan Gain pada penelitian ini adalah Indeks Prestasi Kumulatif (IPK), Jumlah SKS yang telah ditempuh, Semester dan Status perkuliahan mahasiswa angkatan 2013. Pada penelitian ini attribute SKS ditetapkan sebagai node 1 dengan nilai Gain terbesar yaitu 0.3276, yang kemudian di ikuti oleh attribute Semester sebagai node 1.1 dengan nilai Gain sebesar 0.0874
\end{abstract}

Kata kunci: knowledge discovery in database, clasification dan algoritma decesion tree atau C4.5.

\begin{abstract}
Data mining is a knowledge which is engaged in the extraction and analysis of data, where data mining can provide solutions in solving problems, especially those faced by the study program Information Systems Faculty of Computer Science, to ensure that students of Information Systems Faculty of Computer Science University of Bina Darma can be graduated on time. As for the stages used in this research is using the concept of Knowledge Discovery in Databases (KDD), which consists of Selection, Pre - Processing, Transformation, Data Mining and Interprestation / Evaluation. In this study used Clasificassion method and C4.5 or Decision Tree algorithm, In this algorithm, the results of assessments are used to determine the node as a key to assess the feasibility of students that can be drop out views on the value of Entropy and Gain on each attribute, the attributes used for the assessment of Entropy and Gain in this study is the grade point average (GPA), number of credits that have been taken, and the Status of students' Semester force in 2013. In this study, SKS attribute set as node 1 with the largest Gain value is 0.3276, then followed by Semester attribute as node 1.1 with a Gain value of 0.0874
\end{abstract}

Keywords: knowledge discovery in database, clasification and algoritma decesion tree or C4.5.

\section{PENDAHULUAN}

Kemajuan akan ilmu dan pengetahuan pada saat ini sudah tidak dapat terbendung lagi, hal ini merupakan sesuatu yang sangat dibutuhkan guna menjamin kelangsungan hidup manusia dimana peranan akan ilmu dan pengetahun sangat melekat pada kehidupan sehari - hari. Setiap bidang baik di lingkungan pemerintahan maupun swasta telah banyak menggunakan kemajuan ilmu dan pengetahuan baik yang tercipta dalam bentuk perangkat keras maupun perangkat lunak. Dalam penggunaan perangkat perangkat ini dapat tercipta suatu sumber data yang sangat besar sesuai dengan masa pakai dari perangkat yang bersangkutan. Data - data yang tercipta dapat dimanfaatkan untuk hal - hal dimasa yang akan datang baik yang bersifat prediksi, klasifikasi maupun dalam mengasosiasikan sesuatu, hal ini menjadi salah satu faktor pendorong terciptanya suatu bidang ilmu Data Mining. [3] Data Mining merupakan suatu disiplin ilmu yang mempelajari metode untuk mengestrak pengetahuan atau menemukanpola dari suatu data. 
Data mining sering juga disebut dengan Knowledge Discovery in Databases (KDD) sebagai suatu kegiatan yang meliputi pengumpulan, pemakaian data historis untuk menemukan keteraturan, pola atau hubungan dalam set yang berukuran besar. Keluaran dari proses data mining ini dapat dipakai untuk memperbaiki pengambilan keputusan - keputusan di masa yang akan datang [4] guna meningkatkan produktivitas perkuliahan dan kualitas lulusan, Program Studi Sistem Informasi Universitas Bina Darma melakukan kajian - kajian terhadap data - data lulusan untuk melakukan peringatan dini akan kendala kendala yang di hadapi mahasiswa dalam melakukan perkuliahan agar lulus tepat waktu, hal ini di lakukan untuk menghindari adanya mahasiswa yang mengalami drop out yang di lihat dari sisi SKS perkuliahan, IPK dan Jumlah Semester yang telah di lalui. Dengan mengetahui kendala akademik dari mahasiswa khususnya pada Program Studi Sistem Informasi diharapkan dapat sesegera mungkin melakukan pembimbingan dengan mahasiswa - mahasiswa yang berkemungkinan mengalami drop out.

\section{METODOLOGI}

\subsection{Knowledge Discovery in Database (KDD)}

KDD merupakan suatu pola kegiatan non -trivial ( tidak biasa ) guna untuk mencari serta mengidentifikasi pola (pattern) yang terjadi pada sekumpulan data, dimana pola yang ditemukan bersifat sah (yang sebenarnya) baru dapat bermanfaat dan dapat dimengerti. Adapun KDD berhubungan dengan hal - hal yang bersifat teknik integrasi dan penemuan ilmiah, interprestasi dan visualisasi dari pola- pola sejumlah kumpulan data [2]. Adapun tahapan dari KDD dapat dilihat pada Gambar 1 dibawah:

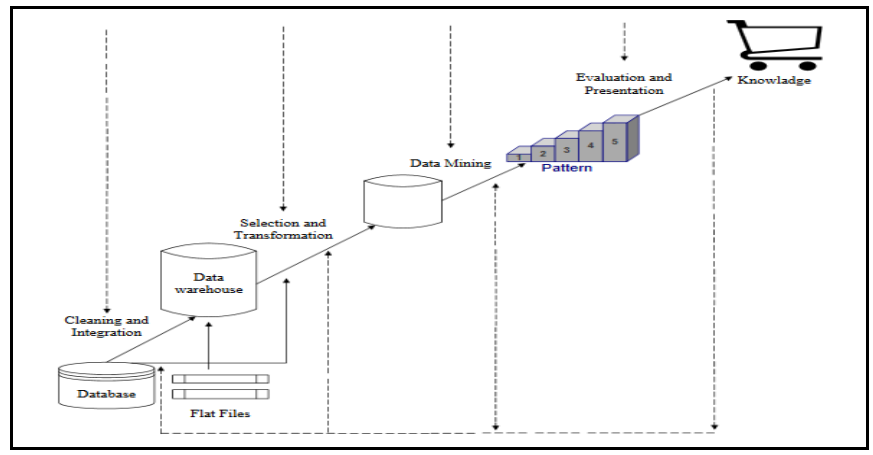

Gambar 1. Tahapan KDD [3]

1. Data Selection

a) Membuat kumpulan atau himpunan dari data target, pemilihan kumpulan data dengan pola tertentu, atau memfokuskan pada variable data atau sampel, dimana proses kegiatan aktivitas penemuan (discovery) dilakukan.

b) Pemilihan / seleksi data - data dari sekumpulan data yang memiliki keterkaitan hubungan secara operasional perlu dilakukan terlebih dahulu yang kemudian baru dapat melanjutkan ke tahap penggalian informasi yang ada ke dalam proses KDD. Kumpulan taau himpunan data hasil dari proses seleksi yang akan digunakan pada proses data mining disimpan dalam suatu tempat / berkas yang terpisah dari kumpulan basis data operasional yang menjadi sumber data.

2. Pre-processing / Cleaning

a) Pre - Processing merupakan operasi yang paling dasar dilakukan seperti menghilangkan noise dilakukan. Barulah proses data mining dapat dilaksanakan, perlu dilakukan terlebuh dahulu proses cleaning pada kumpulan data set yang menjadi data set awal pada proses KDD.

b) Proses cleaning meliputi kegiatan antara lain membuang data duplikat serta memeriksa data yang tidak konsisten atau relevan, kemudian memperbaiki kesalahan pada data tersebut.

c) Dilakukan proses enrichment / memperkaya data set dengan data lain atau informasi lain (eksternal)

3. Transformation

a) Pencarian pola - pola pada data serta hubungan antar fitur yang terdapat pada data / keterkaitan data.

b) Keterkaitan attribute atau fitur yang dipakai untuk menampilkan data bergantung kepada hasil yang ingin di peroleh. 
c) Merupakan proses perubahan/penggabungan (transformasi) pada data set yang telah dipilih.

4. Data mining

a) Melakukan proses Pemilihan tugas serta pemilihan hasil dari proses KDD misalnya klasifikasi, regresi, clustering, dll.

b) Pemilihan metode algoritma data mining yang akan dipakai.

c) Melakukan proses Data mining yaitu proses mencari pola - pola atau informasi yang menarik dalam data set yang terpilih dengan menggunakan teknik serta metode tertentu.

5. Interpretation/ Evaluation

a) Penerjemahan pola / pattern yang terjadi / pola yang dihasilkan dari proses data mining.

b) Pola / pattern informasi yang dihasilkan dari proses data mining akan ditampilkan dalam format / bentuk yang mudah dimengerti oleh pihak yang berkepentingan

\subsection{Algoritma Decision Tree / C4.5}

Decision Tree adalah teknik model prediksi yang digunakan untuk melakukan proses klasifikasi, clustering, serta proses prediksi. Decision Tree menggunakan teknik "membagi dan menaklukkan" untuk membagi ruang pencarian masalah menjadi himpunan masalah [1]. Decision Tree dapat digunakan untuk melakukan proses klasifikasi terhadap sekumpulan objek atau record. Teknik terdiri dari beberapa decision node yang dihubungkan oleh cabang, bergerak ke bawah dari Root Node sampai berakhir di Leaf Node [5]. Algoritma C4.5 merupakan algoritma yang digunakan untukmembentuk pohon keputusan.Secara umum algoritma C4.5 untuk membangun pohon keputusan adalah sebagai berikut:

1) Mempersiapkan data training. Data training merupakan data - data yang pernah terjadi sebelumnya atau disebut data masa lalu serta telah mengalami pengelompokan ke dalam kelas tertentu.

2) Menghitung akar dari pohon Akar akan diambil dari attribute yang akan terpilih dengan cara menghitung nilai gain dari setiap attribute kemudian nilai gain attribute yang tertinggi akan menjadi akar pertama atau node pertama. Sebelum menghitung nilai gain dari attribute hitung dahulu nilai entropy Untuk menghitung nilai entropy digunakan Rumus 1 dibawah:.

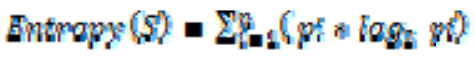

Keterangan :

$\mathrm{S}=$ Himpunan kasus $\mathrm{n}=$ jumlah partisi $\mathrm{S}$

$\mathrm{Pi}=$ proporsi $\mathrm{Si}$ terhadap $\mathrm{S}$

Kemudian hitung nilai gain menggunakan Rumus 2 dibawah :

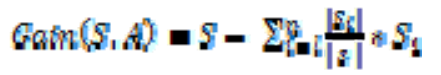

Keterangan :

$\mathrm{S}=$ Himpunan Kasus

$\mathrm{A}=$ Fitur

$\mathrm{n}=$ jumlah partisi attribute A

$|\mathrm{Si}|=$ Proporsi Si terhadap $\mathrm{S}$

$|\mathrm{S}|=$ jumlah kasus dalam $\mathrm{S}$

3) Kemudian untuk tahap selanjutnya mengulangi proses 2 dan 3 hingga semua record terproses. Proses pohon keputusan akan berhenti saat :

a. Semua record dalam nilai $\mathrm{N}$ mendapat kelas yang sama.

b. Tidak ada attribute di dalam record yang diproses lagi

c. Tidak ada record yang menjadi cabang yang kosong

Sehingga akan diperoleh nilai Gain dari attribute yang paling tertinggi. Gain adalah salah satu attribute tiap node pada tree. attribute dengan nilai Gain tertinggi akan dipilih sebagai test attribute untuk node berikutnya. 


\section{Hasil dan Pembahasan}

\subsection{Hasil}

1) Data Cleaning ( Pembersihan Data )

Pembersihan data sumber, yakni membuang data yang tidak konsisten dan noise / redudancy data.

2) Data Integration

Tahap integrasi data merupakan tahap penggabungan data dari berbagai sumber yang terkait dengan kebutuhan penelitian. Data set yang digunakan merupakan data mahasiswa program studi Sistem Informasi Fakultas Ilmu Komputer berasal dari satu sumber yaitu Unit Pelaksana Teknis - Sistem Informasi Manajemen (UPT-SIM), dan dari data yang ada tersebut dapat digunakan untuk pengolahan data mining dengan teknik Decission Tree dengan menggunakan algoritma C4.5.

3) Data Selection.

Proses seleksi data dilakukan dengan cara melihat kecenderungan data serta kesesuaian data dengan topic atau judul penelitian yang akan diteliti oleh penulis, ada pun data yang dipakai terdiri dari attribute Nim, Nama, Program Studi, Status, IPK, Sks dan Semester yang di peroleh dari Unit Pelaksana Teknis - Sistem Informasi Manajemen (UPT-SIM). Adapun data Set dapat dilihat pada Gambar 2 dibawah :

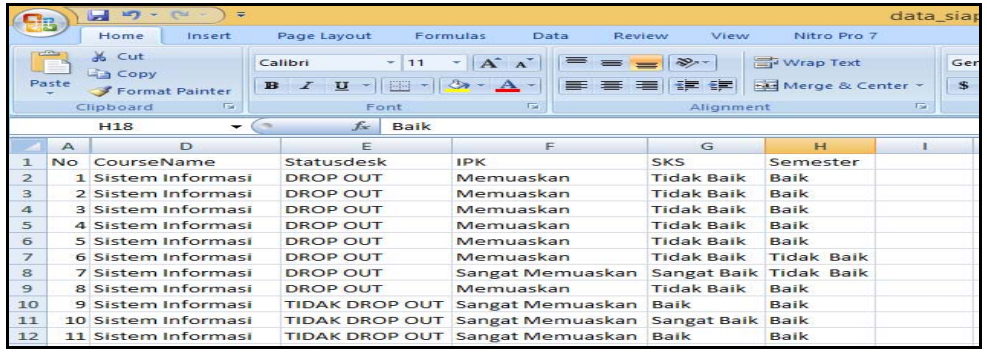

Gambar 2. Data Set Selection

4) Data Transformasi

Pada tahapan ini attribute Ipk, Sks, Status dan Semester akan diberi label mengikuti kondisi data data yang pada attribute tersebut sebagai berikut :

a. Label Ipk

Pada attribute ipk dilakukan proses pengelompokan pada tingkatan skala yang dapat dilihat pada Tabel 1 di bawah sebagai berikut:

Tabel 1. Label attribute IPK

\begin{tabular}{clll}
\hline No & Keterangan & \multicolumn{2}{c}{$\begin{array}{c}\text { Skala } \\
\text { Nilai }\end{array}$} \\
\hline 1 & Memuaskan & 2,25 & - \\
& & 2,75 & \\
2 & Sangat & 2,76 & - \\
& Memuaskan & 3,50 & \\
3 & Cumlaude & 3,51 & - \\
& & 4,00 & \\
\hline
\end{tabular}

b. Label SKS

Pada attribute sks akan dilakukan proses label dengan melihat jumlah sks yang telah di tempuh oleh mahasiswa, ada pun skala jumlah SKS untuk proses label dapat di lihat pada Tabel 2 dibawah :

Tabel 2. Label attribute SKS

\begin{tabular}{|c|c|c|}
\hline No & Keterangan & $\begin{array}{c}\text { Skala } \\
\text { SKS }\end{array}$ \\
\hline 1 & $\begin{array}{l}\text { Sangat } \\
\text { Baik }\end{array}$ & $\begin{array}{l}100-130 \\
\text { sks }\end{array}$ \\
\hline 2 & Baik & $\begin{array}{l}50-99 \\
\text { sks }\end{array}$ \\
\hline 3 & Tidak Baik & $1-40 \mathrm{ks}$ \\
\hline
\end{tabular}


c. Label Semester

Adapun label yang akan diberikan pada attribute semester dapat dilihat pada Tabel 3 berikut :

Tabel 3. Label attribute semester

\begin{tabular}{cll}
\hline No & Label & \multicolumn{1}{c}{ Keterangan } \\
\hline 1 & Baik & Mahasiswa dengan nim tanpa akhiran P \\
2 & Tidak & Mahasiswa dengan nim akhiran P \\
& Baik & \\
\hline
\end{tabular}

d. Label Status Desk

Pada attribute status desk dilakukan klasifikasi sebagai berikut: AKTIF, keluar, TANPA KABAR, STOP OUT, ALUMNI. Attribute StatusDesk ini akan dijadikan class yang merupakan parameter dalam proses pembentukan pohon keputusan Decission Tree dengan menggunakan algoritma C4.5 yang merupakan tolak ukur untuk menentukan mahsiswa dengan status Drop Out atau Tidak Drop Out. Adapun proses label dapat dilihat pada Tabel 4 dibawah.

Tabel 4. Label attribute statusdesk

\begin{tabular}{cll}
\hline No & \multicolumn{1}{c}{ Label } & Nilai Attribute \\
\hline 1 & Tidak Drop Out & Aktif \\
2 & Drop Out & keluar \\
& & Tanpa Kabar \\
& & Alumni \\
& & Stop Out \\
\hline
\end{tabular}

Setelah selesai suluruh tahapan persiapan data set, adapun hasil dari proses tersebut dapat dilihat pada Gambar 3 dibawah yang kemudian disimpan dalam format CSV sehingga dapat di proses oleh Rapidminer:

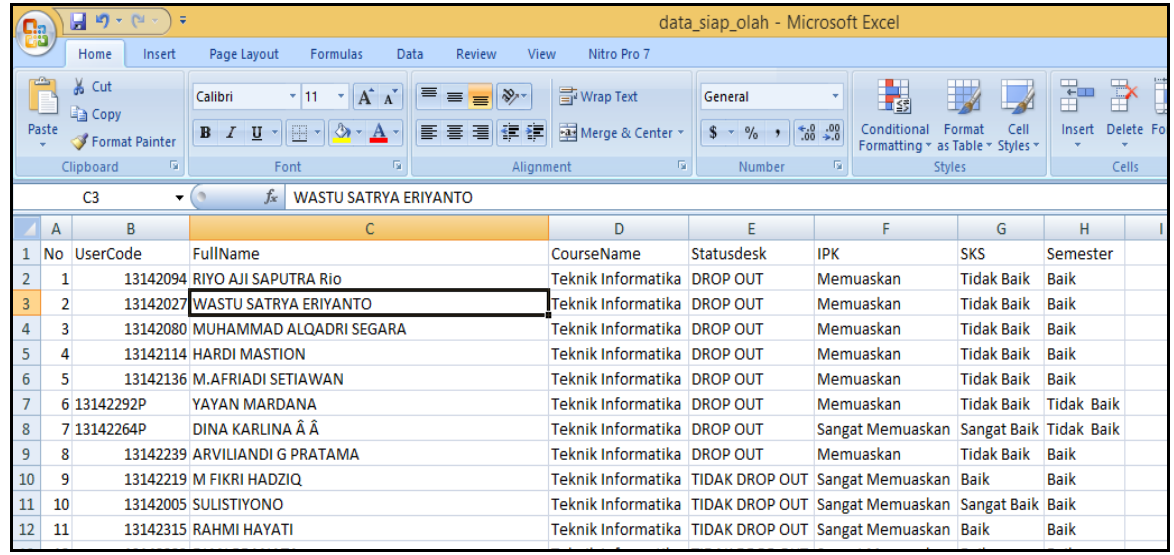

Gambar 3. Data Set Siap Olah

\subsection{Model Rapidminer}

Adapun tampilan dari struktur model data mining yang di gunakan terdiri dari beberapa objek / operator antara lain read file CSV, selected attribute dan Cros Validation yang tampil pada proses utama untuk menjalankan proses data mining. Bentuk dari model Rapidminer dapat di lihat pada Gambar 4 sebagai berikut : 


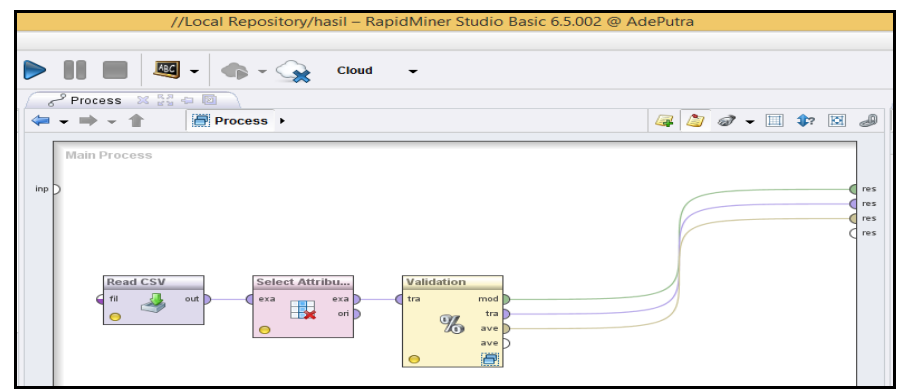

Gambar 4. Rapidminer Model Proses Clasification Decision Tree

Pada objek / operator Cross Validation terdapat sub proses yang terdiri dari operator Decision Tree sebagai algoritma yang di gunakan pada proses data mining Classification yang akan di lakukan, operator Apply Model dan operator Performance sebagai operator untuk menghasilkan pengolahan data mining berupa Decision Tree. Adapun model sub proses dapat di lihat pada Gambar 5 sebagai berikut:

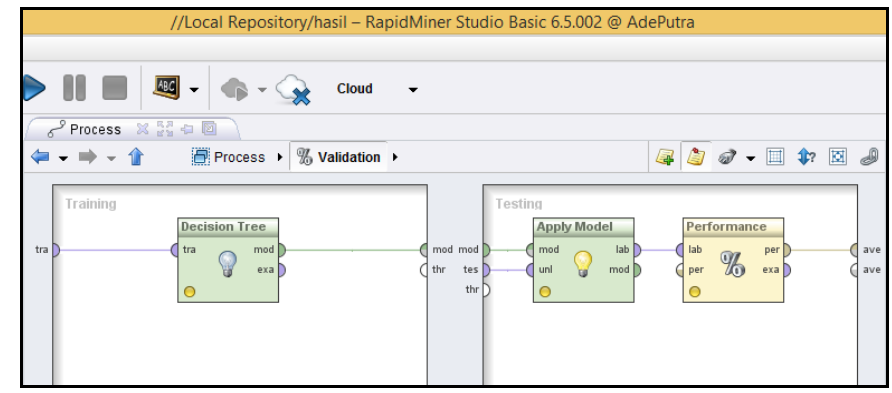

Gambar 5. Rapidminer Model Sub Proses Clasification Decision Tree

Ada pun hasil dari model Rapidminer diatas menghasilkan tampilan Decision Tree yang dapat dilihat pada Gambar 6 sebagai berikut :

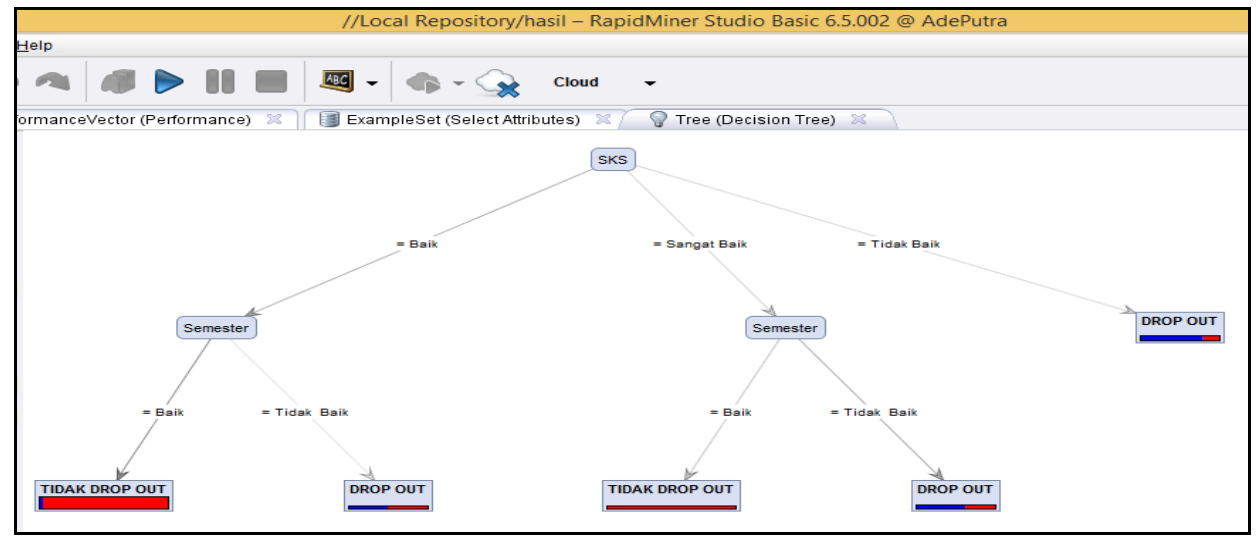

Gambar 6. Decision Tree Prediksi Mahasiswa Drop Out Program Studi Sistem Informasi

\subsection{Pembahasan}

\subsubsection{Perhitungan Tabel berdasarkan Node Attribute}

Tabel perhitungan Node akan dibentuk berdasarkan data yang telah siap yang nantinya akan diuji dengan menggunakan software data mining, berikut pada Tabel 5 akan dilakukan proses secara teoritis perhitungan Entrophy dan Gain dari masing - masing Attribute untuk menentukan Node 1: 
Tabel 5. Perhitungan entrophy dan gain node 1

\begin{tabular}{|c|c|c|c|c|c|c|c|}
\hline NODE & \multicolumn{2}{|c|}{ Keterangan } & $\begin{array}{c}\text { Jumlah } \\
\text { Kasus }\end{array}$ & $\begin{array}{c}\text { Drop } \\
\text { Out }\end{array}$ & $\begin{array}{c}\text { Tidak Drop } \\
\text { Out }\end{array}$ & Entropy & Gain \\
\hline \multirow[t]{12}{*}{1} & & & 287 & 69 & 218 & 0.7957 & \multirow{5}{*}{0.0742} \\
\hline & IPK & Cumlaude & 19 & 5 & 14 & 0.8315 & \\
\hline & \multirow{7}{*}{ SKS } & Sangat & 188 & 27 & 161 & 0.5936 & \\
\hline & & Memuaskan & & & & & \\
\hline & & Memuaskan & 80 & 37 & 43 & 0.9959 & \\
\hline & & & & & & & \multirow[t]{4}{*}{0.3276} \\
\hline & & Sangat Baik & 53 & 22 & 31 & 0.963 & \\
\hline & & Baik & 185 & 8 & 177 & 0.257 & \\
\hline & & Tidak Baik & 49 & 39 & 10 & 0.73 & \\
\hline & \multirow{3}{*}{ SEMESTER } & & & & & & \multirow[t]{3}{*}{0.0938} \\
\hline & & Baik & 245 & 42 & 203 & 0.661 & \\
\hline & & Tidak Baik & 42 & 27 & 15 & 0.9403 & \\
\hline
\end{tabular}

Pada hasil perhitungan untuk node 1 dapat dilihat nilai dari Gain SKS merupakan nilai tertinggi dibandingkan dengan Gain IPK dan Semester sehingga SKS dapat dijadikan Node 1 dalam pembentukan Pohon Keputusan / Decession Tree. Adapun pembentukan Node 1 dapat dilihat pada Gambar 7 dibawah :

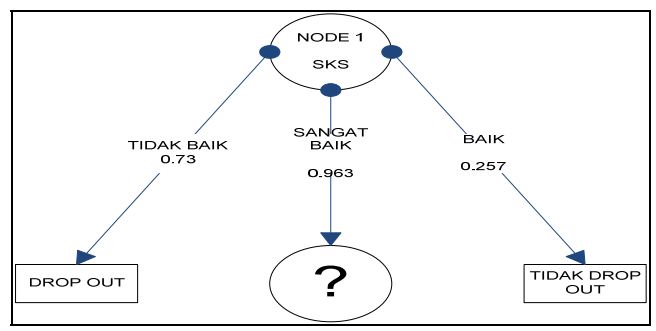

Gambar 7. Pohon Keputusan / Decision Tree Node 1

Untuk proses selanjutnya dalam menetukan Node berikutnya dapat dilakukan dengan cara yang sama sampai pada Node terakhir. Pada Tabel 6 merupakan pembentukan Node 1.1:

Tabel 6. Perhitungan Entrophy dan Gain Node 1.1

\begin{tabular}{|c|c|c|c|c|c|c|c|}
\hline NODE & \multicolumn{2}{|c|}{ Keterangan } & $\begin{array}{c}\text { Jumlah } \\
\text { Kasus }\end{array}$ & $\begin{array}{c}\text { Drop } \\
\text { Out }\end{array}$ & $\begin{array}{c}\text { Tidak } \\
\text { Drop } \\
\text { Out }\end{array}$ & Entropy & Gain \\
\hline \multirow[t]{10}{*}{1.1} & SKS & & 185 & 8 & 177 & 0.257 & \multirow{5}{*}{0.0328} \\
\hline & \multirow[t]{6}{*}{ IPK } & & & & & & \\
\hline & & & & & & & \\
\hline & & Cumlaude & 11 & 6 & 31 & 0.6395 & \\
\hline & & Sangat & 137 & 2 & 135 & 0.2186 & \\
\hline & & Memuaskan & & & & & \\
\hline & & Memuaskan & 37 & 0 & 11 & 0 & \multirow{4}{*}{0.0874} \\
\hline & \multirow[t]{3}{*}{ SEMESTER } & & & & & & \\
\hline & & Baik & 181 & 6 & 175 & 0.2099 & \\
\hline & & Tidak Baik & 4 & 8 & 2 & -1.6534 & \\
\hline
\end{tabular}

Dari hasil perhitungan Node 1.1 dapat dilihat nilai dari Gain Semester menupakan nilai Gain tertinggi di bandingkan dengan nilai Gain IPK, sehingga Semester dapat dijadikan Node berikutnya dapat dilihat pada Gambar 8 : 


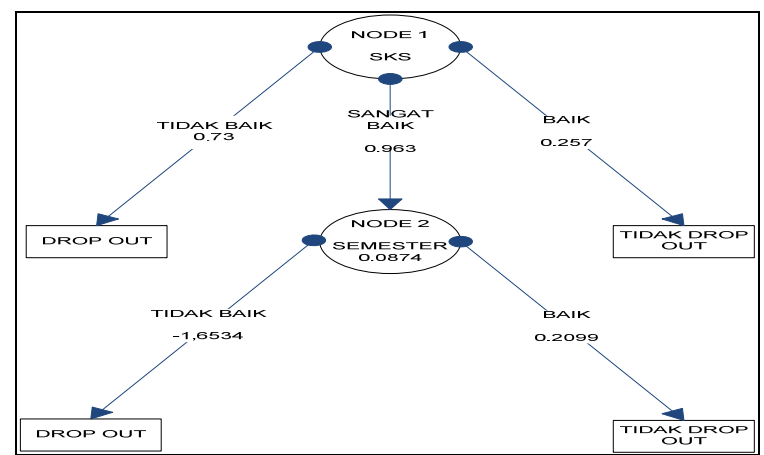

Gambar 8. Pohon Keputusan / Decision Tree Node 1.1

\section{KESIMPULAN}

Dengan memperhatikan bentuk dari pohon keputusan diatas dapat diketahui bahwa semua attribute sudah masuk kedalam class pada pohon keputusan, setelah pohon keputusan terbentuk dapat ditarik kesimpulan sebagai berikut :

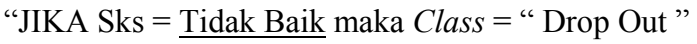

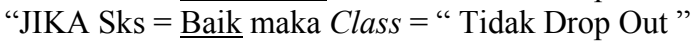

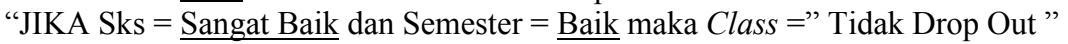

"JIKA Sks $=\underline{\text { Sangat Baik }}$ dan Semester $=$ Tidak Baik maka Class $=$ " Drop Out"

Sehingga pihak Program Studi Sistem Informasi Fakultas Ilmu Komputer Universitas Bina Darma dapat melakukan pembimbingan terhadap mahasiswa yang memiliki jumlah SKS yang Tidak baik dan jumlah Semester yang Tidak Baik sehingga mahasiswa yang bersangkutan dapat lulus dengan tepat waktu.

\section{DAFTAR PUSTAKA}

[1] Dunham, Margareth H. (2003) .Data Mining Introductory and Advanced Topics. New Jersey: Prentice Hall

[2] Fayyad, Usama. (1996). Advances in Knowledge Discovery and Data Mining. MIT Press.

[3] Han, Jiawei dan Kamber, Micheline.(2006), Data Mining : Concept and Techniques Second Edition, Morgan Kaufmann Publishers.

[4] Santosa, Budi (2007). Data Mining Teknik Pemanfaatan Data untuk Keperluan Bisnis. Yogyakarta : Graha Ilmu.

[5] Yusuf, W. Y. (2007). Perbandingan Performansi Algoritma Decision Tree C5.0, CART dan CHAID : Kasus Prediksi Status Resiko Kredit di Bank X. Seminar SNATI. http://journal.uii.ac.id/index.php/Snati/article/view/1628 diakses tanggal 25 Januari 2017. 